\title{
Genetic monitoring reveals loss of microsatellite diversity in a breeding population of the endangered Alabama red-bellied turtle
}

\author{
Elizabeth E. Hieb ${ }^{1, *}$, David H. Nelson ${ }^{1}$, Ashley B. Morris ${ }^{2}$ \\ ${ }^{1}$ Department of Biology, University of South Alabama, Mobile, Alabama 36688, USA \\ ${ }^{2}$ Department of Biology, Middle Tennessee State University, Murfreesboro, Tennessee 37138, USA
}

\begin{abstract}
Genetic monitoring is becoming an increasingly effective tool for determining population stability in endangered species. Evaluating trends in genetic diversity allows conservation managers to identify serious declines and possible extinction risks for threatened populations. Here we used microsatellite analyses to assess the stability of one of the largest known breeding populations of the endangered Alabama red-bellied turtle Pseudemys alabamensis. A total of 238 hatchling specimens were collected over a 9 yr period and analyzed using 6 microsatellite loci. We found no indication of genetic structure within the sample group, indicating that these specimens represent the reproductive output of a single turtle population over 9 consecutive breeding seasons. Measures of genetic diversity, including $F_{\mathrm{ST}}$ values, expected heterozygosity, allelic richness, private allelic richness, and level of inbreeding, were calculated in order to assess the stability of the population over the $9 \mathrm{yr}$ study period. We detected the impacts of genetic drift within the population as a significant change in allele frequencies $\left(F_{\mathrm{ST}}\right)$ over the study period. We also observed a significant level of inbreeding within this population. We estimated the average effective number of breeders over the study period as $N_{b}=25$, indicating a low number of mature adults contributing to reproductive output each year. Results signal a possible decline in population numbers of Alabama red-bellied turtles and may be critical in assessing current and future conservation measures for this endangered species.
\end{abstract}

KEY WORDS: Conservation genetics $\cdot$ Road-kill $\cdot$ Long-term study $\cdot$ Genetic diversity $\cdot$ Pseudemys alabamensis

Resale or republication not permitted without written consent of the publisher

\section{INTRODUCTION}

The ability to accurately evaluate the population status of an endangered species is essential to the success of any conservation strategy. Conservation managers must monitor population trends in order to detect serious declines and extinction risks and to evaluate the effectiveness of current conservation measures (Staples et al. 2005, Marsh \& Trenham 2008). Unfortunately, traditional monitoring methods can often be difficult to undertake and do not always provide an accurate description of a population's parameters. For example, in many species, sampling techniques are limited by geographic and other logistical concerns or only target specific classes within a population (i.e. egg vs. adult, male vs. female; Holmes 2001). Without precise population data, especially for an already threatened species, conservation managers may be unable to identify a decline in population size before it reaches a critical level from which the decline cannot be reversed (Holmes 2001, Staples et al. 2005).

In response to these concerns, molecular techniques have become common tools in population studies. Population genetic monitoring is superior to traditional mark-recapture sampling methods in 
yielding information on population changes and evolutionary processes over shorter time spans (Luikart et al. 2003, Schwartz et al. 2007). Genetic monitoring can determine population structure and characteristics such as genetic diversity, effective population size $\left(N_{\mathrm{e}}\right)$, and level of inbreeding (Waples \& Teel 1990, Hauser et al. 2002, Schwartz et al. 2007, Charlier et al. 2012). These characteristics can be used to infer data on species abundance and the extent of gene flow occurring among populations. Changes in genetic measures over time may signal potentially devastating demographic changes in an imperiled population.

In this study, we implemented genetic monitoring to assess the stability of one of the largest known breeding populations of the endangered Alabama red-bellied turtle Pseudemys alabamensis Baur, 1893. P. alabamensis is restricted to the southernmost regions of the Mobile-Tensaw Delta in Alabama and the Pascagoula River system in Mississippi, USA (Leary et al. 2008). Here, we focus on a breeding population found largely within the Blakeley River in Baldwin County, Alabama. P. alabamensis is currently listed as an endangered species by both the International Union for Conservation of Nature (IUCN; Tortoise \& Freshwater Turtle Specialist Group 1996) and the US Fish and Wildlife Service (USFWS 1987). Major factors contributing to the decline of this species include increased egg and hatchling predation by indigenous wildlife and increased human disturbance of nesting sites (Dobie \& Bagley 1990, Nelson \& Turner 2004, Leary et al. 2008). Our objectives were to use genetic data from road-killed $P$. alabamensis hatchlings collected over nearly a decade to evaluate the genetic structure and possible presence of sub-populations within the turtle population, the stability of the population in terms of genetic diversity, and the effective number of breeders across years. Objectives of this study directly coincide with objectives of the current Alabama red-bellied turtle recovery plan (Dobie \& Bagley 1990), and results presented here provide valuable information for planning future conservation management of the Endangered Alabama red-bellied turtle.

\section{MATERIALS AND METHODS}

\section{Sample collection}

Pseudemys alabamensis specimens used in this study were collected between 2004 and 2012 as part of an ongoing turtle road-kill mortality survey along the US Highway 90/98 causeway crossing Mobile Bay, Alabama (Nelson 2009). The causeway is a 4lane paved roadway stretching 7.5 miles $(\sim 12 \mathrm{~km})$ from Mobile, Alabama (Mobile County) to Spanish Fort, Alabama (Baldwin County). The causeway intersects the freshwater deltas of the Tensaw, Apalachee, and Blakeley Rivers, crossing several nesting areas used by one of the largest known breeding populations of $P$. alabamensis (Fig. 1). Turtles can easily access the causeway due to its low elevation (usually $<1 \mathrm{~m}$ above the surrounding waterways) and are often killed by passing vehicles. Newly emerged hatchlings comprise the majority of road-kill specimens recorded. Between 2004 and 2012, a total of 356 road-kill hatchlings were collected along the causeway (Nelson 2009, 2013). An additional 20 roadkill hatchlings were collected on roadways adjacent to the causeway (D.H.N., unpubl. data). Two live hatchlings were also collected from the causeway, but later died while temporarily housed at the University of South Alabama (D.H.N., unpubl. data). All specimens were preserved either cryogenically or in alcohol (50\% isopropanol or $95 \%$ ethanol) in the University of South Alabama Vertebrate Natural History Collection. Tissue samples for genetic analysis were taken from specimens as 5 to $10 \mathrm{~mm}$ tail snips; if a tail was too severely damaged by road-kill impact, samples were instead taken from foot tissue (tail tissue, $\mathrm{n}=149$; foot tissue, $\mathrm{n}=17$; combined tail and foot tissue, $\mathrm{n}=122$ ).

$P$. alabamensis females typically nest during the warm summer months, with peak nesting occurring in early July. Some hatchlings emerge in the fall,

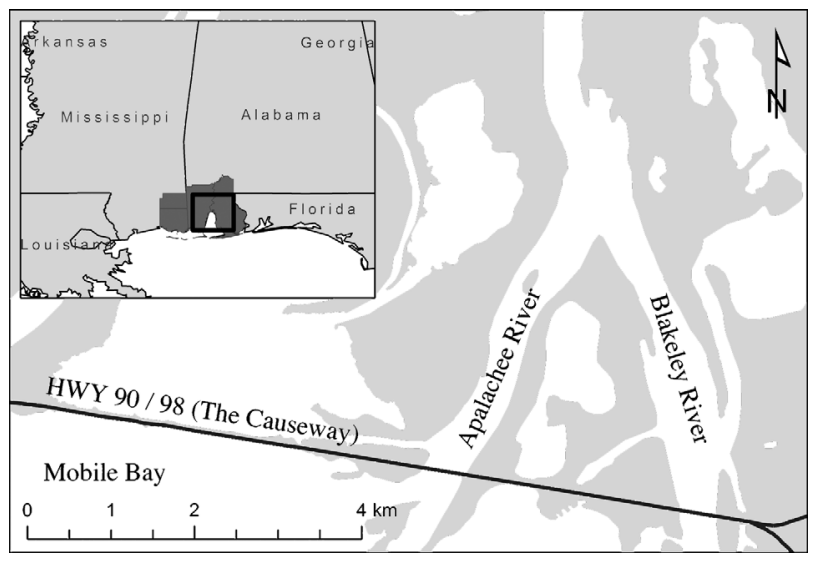

Fig. 1. Pseudemys alabamensis. Distribution of the endangered Alabama red-bellied turtle within the southern-most region of the Mobile-Tensaw Delta, USA. Hwy 90/98: the causeway representing the sampling area for the current study. Inset: the extant species range within a broader geographic context 
from September to November; however, most hatchlings overwinter, remaining dormant in the nests and postponing emergence until March or April of the next year (Nelson 2001, 2003, Nelson et al. 2009). Due to this overwintering behavior, road-kill sample collection years do not always correspond to breeding/nesting years. Since our analyses are aimed at comparing reproductive output and diversity across years, hatchlings are grouped according to the breeding/nesting year in which they were produced (2003 to 2011) instead of the year in which they were collected (2004 to 2012).

\section{Genotyping}

Total genomic DNA was extracted from all samples using the DNeasy Blood and Tissue Kit (Qiagen) following the manufacturer's instructions. Amplification of DNA was performed at the following 6 microsatellite loci characterized for use in $P$. alabamensis by Hieb et al. (2011): GmuB08, GmuB91, GmuD28, GmuD55, GmuD79, and GmuD87. Amplification followed the methods of King \& Julian (2004), with minor adjustments to allow for an M13-tailed primer approach for fluorescent tagging of products (Oetting et al. 1995) as described by Hieb et al. (2011). Amplified products were analyzed on an ABI 3730 XL DNA Analyzer at Cornell University Life Sciences Core Laboratories Center, Ithaca, New York. Results were scored by eye using Peak Scanner Software V. 1.0 (Applied Biosystems). Accuracy of allele size calling was checked by binning based on raw size using AUTOBIN (an Excel macro available at www4. bordeaux-aquitaine.inra.fr/biogeco/Resources/Logi ciels/Autobin; see Guichoux et al. 2011). A total of 238 hatchlings collected over 9 yr were successfully genotyped across all loci.

\section{Genetic analyses}

Genotypes of hatchling turtles from all sample years were tested for linkage disequilibrium (LD) and deviations from Hardy-Weinberg equilibrium (HWE) using GENEPOP V. 4.0.1 (Raymond \& Rousset 1995, Rousset 2008). We examined genetic structure and the possible presence of sub-populations within the study population using Structure V. 2.3 (Pritchard et al. 2000), which uses a Bayesian clustering approach to assign individuals to population/sub-population groupings (clusters). To find the most likely assignments to number of clus- ters $(K)$ within the sample set, we performed 3 runs for each $K$, ranging from 1 to 9, with a burnin period of 100000 Markov-Chain Monte Carlo (MCMC) steps followed by 100000 replications. Since there is little information available on gene flow across the $P$. alabamensis distribution, we tested models under all possible combinations of assumptions regarding the occurrence of admixture/no admixture within individual genomes and correlated/uncorrelated allele frequencies among populations. Results from Structure V. 2.3 were input into the program Structure Harvester (Earl \& vonHoldt 2012), which uses the method of Evanno et al. (2005) to calculate the most likely $K$ for the data set.

We used several measures to assess the stability of the study population. First, the extent of inbreeding $\left(F_{\mathrm{IS}}\right)$ and associated levels of significance were calculated for each locus and across loci using ARLEQUIN V. 3.11 (Excoffier et al. 2005). We examined changes in allele frequencies across sampling years using $F_{\mathrm{ST}}$ values per locus across all years and pairwise $F_{\mathrm{ST}}$ values between sampling years calculated in ARLEQUIN V. 3.11. To examine trends in genetic diversity across sampling years, we used the following measures: expected heterozygosity $\left(H_{\mathrm{e}}\right)$, allelic richness $\left(A_{\mathrm{R}}\right)$, and private allelic richness $\left(p A_{\mathrm{R}}\right) . H_{\mathrm{e}}$ values were calculated using GENEPOP V. 4.0.1. Both $A_{\mathrm{R}}$ and $p A_{\mathrm{R}}$ values were calculated, implementing rarefaction to correct for differences in sample size, using the program HP-RARE V. 1.0 (Kalinowski 2005). The statistical significance of temporal trends in diversity was tested by running a linear regression of each measure $\left(H_{\mathrm{e}}, A_{\mathrm{R}}, p A_{\mathrm{R}}\right)$ against collection year and calculating Pearson's correlation coefficient (r) of the regressions, both per locus and across loci.

To achieve a more representative sample of the $P$. alabamensis nesting population of interest, we used the program KinGroup V. 2.08 (Konovalov et al. 2004) to assign full-sibling groups within each year and included only 1 member of each sibling group in our temporal analyses of $H_{\mathrm{e}}, A_{\mathrm{R}}$, and $p A_{\mathrm{R}}$. We implemented a combinatorial approach to determine fullsibling groups, first using a Simpson-assisted descending ratio approach to assign sibling groups. Concurrently, we used the method of Queller \& Goodnight (1989) which tests hypotheses of relatedness between pairs of individuals by calculating the ratio of a primary hypothesis (in our case full-sibling relatedness) to a null hypothesis (no relatedness). The significance of the ratio is then determined by simulation. We compared the results of both methods to determine final assignment of full-sibling groups 
within our sample years. If a sibling group was assigned using the Simpson-assisted descending ratio approach and if all members of that group had significant $(p<0.05)$ relatedness values, then only 1 member of this sibling group was included in our analyses.

To estimate the effective number of breeders $\left(N_{\mathrm{b}}\right)$ in each sampling year we used the LD approach implemented by the program LDNE V. 1.31 (Waples 2006, Waples \& Do 2008), which estimates effective population size $\left(N_{\mathrm{e}}\right)$. When estimating $N_{\mathrm{e}}$, the LD method works from a model assuming discrete generations; however, in species such as $P$. alabamensis that have overlapping generations, estimates of $N_{\mathrm{e}}$ can be interpreted as $N_{\mathrm{b}}$ for a given sample group (Waples \& Do 2010). Therefore, $N_{\mathrm{e}}$ for each sampling year can be interpreted as the number of breeders $\left(N_{\mathrm{b}}\right)$ that produced the sampled hatchlings in that year. Estimates were calculated assuming random mating and excluding all alleles with frequencies $<0.02$ (Waples \& Do 2008). We examined potential temporal trends in $N_{\mathrm{b}}$ estimates using a linear regression. Using LDNE we also obtained $95 \%$ confidence intervals for $N_{\mathrm{b}}$ values using both parametric and jackknife methods. Finally, we used $N_{\mathrm{b}}$ estimates for each sampling year to calculate both the weighted and unweighted harmonic mean $N_{\mathrm{b}}$ for the entire 9 yr period (Waples \& Do 2010).

\section{RESULTS}

After Bonferroni correction, there was no significant linkage disequilibrium detected across loci $(\mathrm{p}<$ 0.003 ); however, there were significant deviations from HWE for 4 of the 6 loci used ( $<<0.008$; Table 1). We suspect that deviations from HWE are due to an inherent bias in the road-kill sampling method and not necessarily characteristic of the loci used. The likelihood of a hatchling being road-killed is at least partially dependent on the location of the nest from which it emerges (assuming that hatchlings from nests laid closer to the road are more likely to end up as road-kills). Hatchlings that emerge from the same nest are therefore likely to be road-killed together. For example, in a group of 5 road-kill hatchlings, it is more likely that those 5 hatchlings emerged from the same nest than it is that they emerged from 5 different nests. Since each nest contains a sibling group, when sampling road-kill hatchlings, one is more likely to collect siblings than unrelated individuals. Therefore, deviations from HWE would be expected in this type of collection. Previous results from a
Table 1. Pseudemys alabamensis. Summary statistics for 6 microsatellite loci used to study the Blakeley River, Alabama population of Alabama red-bellied turtles based on 238 hatchlings collected from 2004 to 2012 (breeding years 2003 to 2011). $N_{\mathrm{a}}$ : number of alleles; $H_{\mathrm{e}}$ : expected heterozygosity; $H_{\mathrm{o}}$ : observed heterozygosity; $F_{\mathrm{IS}}$ : inbreeding coefficient; $F_{\mathrm{ST}}$ : fixation index of genetic differentiation among years. ${ }^{* *} \mathrm{p}<$ $0.01,{ }^{* * *} \mathrm{p}<0.001$

\begin{tabular}{|lcccccc|}
\hline Locus & $N_{\mathrm{a}}$ Allele size & $H_{\mathrm{e}}$ & $H_{\mathrm{o}}$ & $F_{\mathrm{IS}}$ & $F_{\mathrm{ST}}$ \\
\multicolumn{7}{c}{ range } \\
\hline GmuB08 & 9 & $225-255$ & 0.75 & 0.74 & -0.009 & -0.0034 \\
GmuB91 & 5 & $148-175$ & 0.28 & 0.25 & -0.110 & -0.0002 \\
GmuD28 & 7 & $180-248$ & 0.67 & 0.68 & -0.009 & -0.0041 \\
GmuD55 & 6 & $185-217$ & 0.18 & 0.14 & $-0.219^{* * *}$ & -0.0035 \\
GmuD79 & 8 & $161-205$ & 0.77 & 0.51 & $-0.303^{* * *}$ & $-0.0591^{* * *}$ \\
GmuD87 & 6 & $240-280$ & 0.53 & 0.66 & -0.272 & $-0.0289^{* *}$ \\
Total & & & & & $-0.049^{* *}$ & $-0.0211^{* * *}$ \\
\hline
\end{tabular}

broader geographic survey of Pseudemys alabamensis showed no deviations from HWE in the same loci used here (Hieb et al. 2011).

\section{Population structure}

Estimates of $K$ within the sample group varied from 2 to 6 depending on the model assumptions used, indicating a lack of power in clustering assignment. Upon closer examination of the results, we determined that structure found within the population was not real. Probabilities of $K[\operatorname{Pr}(K)]$ values were nearly identical across tested $K$ from 1 to 9 . Individual assignments within clusters were highly symmetrical (i.e. the same numbers of individuals were assigned to each cluster), indicating that cluster assignment was random, rather than based on genotypic distribution.

\section{Population stability}

Totaled across loci, there was a significant level of inbreeding (heterozygote deficit) present across sampling years $\left(F_{\mathrm{IS}}=0.049, \mathrm{p}<0.01\right.$; Table 1$)$. For measures of genetic diversity, after Bonferroni correction, there were no significant temporal trends, per locus or across loci, in expected heterozygosity $\left(H_{\mathrm{e}}\right)$, allelic richness $\left(A_{\mathrm{R}}\right)$, or private allelic richness $\left(p A_{R}\right)$ over the sampling period $\left(F_{1,7,8}=5.09, \mathrm{p}=0.06\right.$; $F_{1,7,8}=3.27, \mathrm{p}=0.11$; and $F_{1,7,8}=2.25, \mathrm{p}=0.18$, respectively; Table 2). Both per locus and across loci, $H_{\mathrm{e}}$ and $A_{\mathrm{R}}$ showed negative correlations with years of study (Tables $2 \& 3$ ). $p A_{R}$ showed similar negative correlations in 5 out of 6 loci and totaled across all 
Table 2. Pseudemys alabamensis. Slopes and Pearson's correlation coefficients of regression analysis of genetic diversity measures for the Alabama red-bellied turtle hatchlings sampled. $H_{\mathrm{e}}$ : expected heterozygostiy; $A_{\mathrm{R}}$ : allelic richness; $p A_{\mathrm{R}}$ : private allelic richness

\begin{tabular}{|c|c|c|c|}
\hline Locus & Diversity measure & Pearson & Slope \\
\hline GmuB08 & $\begin{array}{c}H_{\mathrm{e}} \\
A_{\mathrm{R}} \\
p A_{\mathrm{R}}\end{array}$ & $\begin{array}{c}-0.35 \\
-0.27 \\
0.03\end{array}$ & $\begin{array}{l}-0.006 \\
-0.033 \\
-0.002\end{array}$ \\
\hline GmuB91 & $\begin{array}{c}H_{\mathrm{e}} \\
A_{\mathrm{R}} \\
p A_{\mathrm{R}}\end{array}$ & $\begin{array}{l}-0.18 \\
-0.25 \\
-0.45\end{array}$ & $\begin{array}{l}-0.005 \\
-0.036 \\
-0.026\end{array}$ \\
\hline GmuD28 & $\begin{array}{c}H_{\mathrm{e}} \\
A_{\mathrm{R}} \\
p A_{\mathrm{R}}\end{array}$ & $\begin{array}{l}-0.57 \\
-0.42 \\
-0.21\end{array}$ & $\begin{array}{l}-0.012 \\
-0.035 \\
-0.007\end{array}$ \\
\hline GmuD55 & $\begin{array}{c}H_{\mathrm{e}} \\
A_{\mathrm{R}} \\
p A_{\mathrm{R}}\end{array}$ & $\begin{array}{l}-0.03 \\
-0.08 \\
-0.44\end{array}$ & $\begin{array}{l}-0.001 \\
-0.013 \\
-0.019\end{array}$ \\
\hline GmuD79 & $\begin{array}{c}H_{\mathrm{e}} \\
A_{\mathrm{R}} \\
p A_{\mathrm{R}}\end{array}$ & $\begin{array}{l}-0.17 \\
-0.16 \\
-0.31\end{array}$ & $\begin{array}{l}-0.004 \\
-0.029 \\
-0.019\end{array}$ \\
\hline GmuD87 & $\begin{array}{c}H_{\mathrm{e}} \\
A_{\mathrm{R}} \\
p A_{\mathrm{R}}\end{array}$ & $\begin{array}{l}-0.46 \\
-0.52 \\
-0.65\end{array}$ & $\begin{array}{l}-0.011 \\
-0.038 \\
-0.009\end{array}$ \\
\hline All loci & $\begin{array}{c}H_{\mathrm{e}} \\
A_{\mathrm{R}} \\
p A_{\mathrm{R}}\end{array}$ & $\begin{array}{l}-0.65 \\
-0.56 \\
-0.49\end{array}$ & $\begin{array}{l}-0.007 \\
-0.031 \\
-0.013\end{array}$ \\
\hline
\end{tabular}

Table 3. Pseudemys alabamensis. Genetic diversity measures averaged across loci for Alabama red-bellied turtle hatchlings sampled per year. $N$ : sample size; $H_{\mathrm{e}}$ : expected heterozygostiy; $A_{R}$ : allelic richness; $p A_{R}$ : private allelic richness

\begin{tabular}{|ccccc|}
\hline Year & $N$ & $H_{\mathrm{e}}$ & $A_{\mathrm{R}}$ & $p A_{\mathrm{R}}$ \\
\hline 2003 & 14 & 0.53 & 3.19 & 0.11 \\
2004 & 48 & 0.57 & 3.27 & 0.22 \\
2005 & 11 & 0.51 & 2.96 & 0.01 \\
2006 & 55 & 0.50 & 2.94 & 0.04 \\
2007 & 11 & 0.51 & 2.98 & 0.02 \\
2008 & 24 & 0.54 & 3.11 & 0.14 \\
2009 & 22 & 0.47 & 2.79 & 0.03 \\
2010 & 14 & 0.51 & 3.09 & 0.02 \\
2011 & 29 & 0.48 & 2.90 & 0.03 \\
\hline
\end{tabular}

loci (Tables 2 \& 3). Pairwise comparisons between sampling years using $F_{\mathrm{ST}}$ values showed no significant differences among years. However, $F_{\mathrm{ST}}$ values calculated per locus were significant for 2 loci: GmuD79 (p < 0.001) and GmuD87 ( $<<0.01$; Table 1). Because of the observed changes in allele frequencies at these 2 loci, a significant change in $F_{\mathrm{ST}}$ values was found for the entire sampling period $\left(F_{\mathrm{ST}}=0.021\right.$, $\mathrm{p}<0.001$ ), providing evidence for genetic drift over the study period.

\section{Effective number of breeders}

Estimates of $N_{\mathrm{b}}$ per sampling year ranged from 10 to $\infty$ (Table 4). Negative estimates are interpreted as $N_{\mathrm{e}}$ (or $N_{\mathrm{b}}$ ) $=\infty$ meaning that the genotypic distribution for the sample group can be explained entirely by sampling error (Waples \& Do 2010). In other words, observed allele frequencies provide no evidence for LD within the sample group, and a finite population size cannot be estimated. Excluding infinity estimates from years 2003 and 2011, we found no evidence of a temporal trend in $N_{\mathrm{b}}$ estimates over nesting/breeding years from 2004 to $2010\left(F_{1,5,6}=0.60, \mathrm{p}=0.47\right)$. The weighted harmonic mean estimate over the entire sampling period was $N_{\mathrm{b}}=25$. The unweighted harmonic mean estimate was $N_{\mathrm{b}}=54$.

\section{DISCUSSION}

\section{Population structure}

In our examination of the Blakeley River nesting population of Alabama red-bellied turtles, we found no evidence for sub-structuring within the study population. Results from the program Structure initially indicated the presence of multiple sub-populations (clusters) within the sample population, but, upon closer examination, we determined that these clustering assignments were not based on real genetic structure, but were instead an artifact of sampling bias. When determining cluster assignments, Structure assumes a population model in complete HWE.

Table 4. Pseudemys alabamensis. Effective number of breeders per year for the Blakeley River, Alabama red-bellied turtle population. $N_{\mathrm{b}}$ and $95 \%$ confidence intervals (CI) were calculated using the program LDNE; the lowest allele frequency used was 0.02 . N: sample size; $N_{\mathrm{b}}$ : effective number of breeders

\begin{tabular}{|c|c|c|c|c|}
\hline $\begin{array}{l}\text { Breeding } \\
\text { year }\end{array}$ & $\mathrm{N}$ & $N_{\mathrm{b}}$ & $\begin{array}{r}95 \% \\
\text { Parametric }\end{array}$ & $\begin{array}{l}\text { CI } \\
\text { Jackknife }\end{array}$ \\
\hline 2003 & 14 & -104.6 & $12.5-\infty$ & $11.0-\infty$ \\
\hline 2004 & 52 & 25.5 & $15.3-45.6$ & $13.8-54.2$ \\
\hline 2005 & 11 & 10.4 & $1.9-\infty$ & $2.3-\infty$ \\
\hline 2006 & 54 & 278.2 & $45.1-\infty$ & $52.5-\infty$ \\
\hline 2007 & 14 & 138.0 & $8.1-\infty$ & $7.9-\infty$ \\
\hline 2008 & 23 & 58.1 & $13.1-\infty$ & $12.8-\infty$ \\
\hline 2009 & 24 & 371.8 & $18.0-\infty$ & $32.9-\infty$ \\
\hline 2010 & 15 & 55.3 & $7.4-\infty$ & $9.8-\infty$ \\
\hline 2011 & 31 & -133.8 & $45.9-\infty$ & $85.3-\infty$ \\
\hline Total & 238 & $\begin{array}{c}25 \text { (weighted) } \\
54 \text { (unweighted) }\end{array}$ & & \\
\hline
\end{tabular}


Deviations from HWE are then explained by subpopulation structure within the larger population, with sub-populations (clusters) assigned as groupings that are not in disequilibrium (Pritchard et al. 2000). For the sample population, deviations from HWE can be explained by the bias in the sampling method (as discussed in the 'Results' section) and are not indicative of true sub-population structure. We concluded that hatchlings sampled in this study represent the reproductive output of a single Pseudemys alabamensis population $(K=1)$.

\section{Population stability}

Across the 9 yr study period, we found evidence for a decrease in genetic diversity, signaling a possible decline in this $P$. alabamensis population. Expected heterozygosity, allelic richness, and private allelic richness all showed negative correlations with sampling years, though temporal trends were not significant. Calculated $F_{\text {ST }}$ values indicated significant differentiation among sampling years, meaning that there have been significant changes in allele frequencies over the entire period. Similar changes in genetic composition were described in a population of painted turtles Chrysemys picta studied over an $11 \mathrm{yr}$ period (Scribner et al. 1993). These changes were primarily attributed to variation in female reproductive success. Hatchlings from years in which fewer females successfully nested showed reduced heterozygosity and higher inbreeding coefficients $\left(F_{\mathrm{IS}}\right)$ compared to hatchlings produced in years with greater numbers of successfully reproducing females. Similar, annual variations in female reproductive success have been observed in the Blakeley River $P$. alabamensis population, largely due to environmental impact (i.e. drought or flooding due to tropical storms/hurricanes; Nelson 2009, D.H.N. unpubl. data). These variations may at least partially explain genetic differentiation among years seen within the study population.

The observed, temporal changes in allele frequencies for the study population may also be attributed to genetic drift. Even over a short time frame of less than a decade, significant allele frequency shifts can occur in small populations due entirely to genetic drift (Waples \& Teel 1990). Impacts of genetic drift become more pronounced in populations undergoing limited or no migration. There is little information currently available on gene flow among populations across the geographic distribution of $P$. alabamensis. The study population occurs in the southern-most region of the Mobile-Tensaw Delta, bordering the northern end of Mobile Bay. Radio-telemetry studies of turtle movements support the assumption that the study population found in the Blakeley River is geographically isolated from other $P$. alabamensis populations to the south by the brackish, open waters of Mobile Bay (Nelson 2001). However, it is unknown to what extent gene flow occurs between members of the Blakeley River population and turtles found further north in the Mobile-Tensaw Delta. Individual turtles have been tracked over distances of up to 17.9 km (11.1 miles; Nelson 2001), suggesting that turtles found within the delta may represent one continuous population.

Observations of long-distance movements by $P$. alabamensis do not necessarily imply that gene flow is occurring across these distances. Even in highly migratory turtle species, genetic structure has been seen across nesting sites separated by relatively short distances (Valenzuela 2001, Freedberg et al. 2005). Though female philopatry may lead to overestimation of true genetic differentiation at these sites, evidence of segregated breeding groups has been documented in non-philopatric species (Valenzuela 2001). Furthermore, studies by Souza et al. $(2002 a, b)$ on the Brazilian snake-necked turtle Hydromedusa maximiliani found that habitat differentiation within a large river system in southeastern Brazil led to population sub-structuring among various drainages/tributaries within the river system. Similar habitat 'pockets' may occur within the Mobile-Tensaw Delta, limiting gene flow across the $P$. alabamensis distribution.

A significant level of $F_{\text {IS }}$ was also detected within the Blakeley River population. Inbreeding increases homozygosity within a population, swiftly magnifying the impacts of genetic drift (Keller \& Waller 2002). High levels of inbreeding reduce variation within the genome and increase expression of detrimental mutations, causing an overall reduction in fitness of a population (Wright 1921, Lynch et al. 1995). Inbreeding can also severely impact reproductive potential, decreasing sperm quality and quantity (Wildt et al. 1983, Roldan et al. 1998, Gage et al. 2006) and reducing hatching success rates in oviparous species (Bensch et al. 1994, Daniels \& Walters 2000). Additionally, inbreeding has been linked to increased susceptibility to parasitism in a wide array of host taxa (Whiteman et al. 2006, Luong et al. 2007, Charpentier et al. 2008). Of particular interest, in a study of 3 endangered gazelle species, an inverse relationship was found between level of heterozygosity and intensity of parasitism by gastrointestinal nematodes, which are known parasites of the study 
species Pseudemys alabamensis (Cassinello et al. 2001, D.H.N. pers. comm.).

While the level of inbreeding detected in the study population should not be ignored, we also acknowledge that it should be interpreted cautiously. It is unknown whether $P$. alabamensis females return to the same nesting sites over multiple years, but the occurrence of female philopatry would lead to an overestimation of the level of inbreeding within the population (Scribner et al. 1993, Freedberg et al. 2005). Additionally, there is an inherent bias in the road-kill sampling method toward collecting related individuals, specifically siblings. $F_{\text {IS }}$ is a measure of most recent common ancestry; therefore, the presence of siblings in the sample group will also cause an overestimation of inbreeding within the population. The sampling bias, however, does not necessarily negate the presence of a significant level of inbreeding within the study population. Impacts of inbreeding can be especially detrimental to small, endangered populations. Across multiple taxa, significant inbreeding has been shown to drastically reduce time to extinction, by $\sim 25 \%$ for a population of $\mathrm{N}=1000$ (Brook et al. 2002). Further investigation of the level of inbreeding within the Blakeley River $P$. alabamensis population, as well as other populations across the species' range, should be a priority for conservation of the species.

\section{Effective number of breeders}

Across the sampling period we found no evidence of a trend in the numbers of effective breeders per year $\left(N_{\mathrm{b}}\right)$. For the study population, which exhibits overlapping year classes, we would expect the observed short-term changes in allele frequencies to be primarily linked to the number of effective breeders in each year (Waples \& Teel 1990). It may be the case that we were unable to detect changes in $N_{\mathrm{b}}$ due to the limited power of the regression analysis. Since measures of $N_{\mathrm{b}}$ are highly dependent on sample sizes per year, a temporal trend may not be evident based on the given sample group. With equal sample sizes across years, we could potentially detect a significant trend in $N_{\mathrm{b}}$, which would explain the changes in allele frequencies seen in the population.

The weighted and unweighted harmonic mean $N_{\mathrm{b}}$ estimates for the entire study period were $N_{\mathrm{b}}=25$ and $N_{\mathrm{b}}=54$, respectively. The weighted harmonic mean assigns contribution values, 'weights,' of single year $N_{\mathrm{b}}$ estimates to the overall $N_{\mathrm{b}}$ estimate across the study period (Waples \& Do 2010, Charlier et al.
2012). Each 'weight' is a function of sample size and number of independent comparisons (alleles) per year. Weighted harmonic mean estimates are generally regarded as more accurate than unweighted estimates (Waples \& Do 2010). There is also evidence that $N_{\mathrm{b}}$ estimates using the LD approach can be interpreted as effective population size $\left(N_{\mathrm{e}}\right)$ estimates, even in populations with overlapping generations (Charlier et al. 2012). We would then estimate $N_{\mathrm{e}}=25$ for the sample population. Further work is needed to confirm the accuracy of this interpretation.

\section{Implications for conservation}

In conclusion, the data suggest that road-killed Alabama red-bellied turtles sampled over the $9 \mathrm{yr}$ study period represent 1 continuous population found within the Blakeley River, Baldwin County, Alabama, though the level of gene flow among this population and other $P$. alabamensis populations remains unclear. We also present evidence for a decrease in genetic diversity for this population, compounded with a significant level of inbreeding. Though a significant difference among estimates of effective numbers of breeders across years was not seen, genetic diversity results may still indicate a decrease in population size. The high rate of road-kill mortality for this species may be a primary contributor to population decline.

General life-history features of turtle species, such as delayed sexual maturity and high hatchling and juvenile mortality rates, compromise the ability of populations to respond to increased mortality resulting from road-kills (Congdon et al. 1993, Gibbs \& Shriver 2002). Turtle species may be unable to maintain positive population growth when impacted by road-kill mortality, especially when high numbers of sexually mature adults are lost as road-kills (Congdon et al. 1993, Gibbs \& Shriver 2002). Therefore, road-kill mortality remains a severe threat to the Blakeley River P. alabamensis population, and further action may be warranted to reduce the number of road-killed turtles.

The implications of these results on the overall stability of the Blakeley River P. alabamensis population may be critical in assessing current and future conservation measures for this species. There is evidence of significant, short-term genetic drift in the population, potentially caused by declining population numbers. Impacts of genetic drift can be extremely detrimental to small populations, severely reducing heterozygosity and the overall fitness of the 
population. However, the rate of genetic drift fluctuates over time and with changing conditions (Charlier et al. 2012); therefore, continued genetic monitoring of this population is necessary to confirm the results presented here and to obtain a more accurate picture of the $P$. alabamensis population as a whole.

Acknowledgements. Funding for this project was provided by the US Fish and Wildlife Service, the Birmingham Audubon Society's Walter F. Coxe Research Fund, and the University of South Alabama Department of Biology. We acknowledge J. A. Borden, T. G. Jackson, and A. C. Horton for field collection. We also thank C. Partridge and J. S. Howell for assistance with statistical analysis.

\section{LITERATURE CITED}

Baur G (1893) Notes on the classification and taxonomy of the Testudinata. Proc Am Philos Soc 31:210-225

Bensch S, Hasselquist D, von Schantz T (1994) Genetic similarity between parents predicts hatching failure: nonincestuous inbreeding in the great reed warbler? Evolution 48:317-326

Brook BW, Tonkyn DW, O'Grady JJ, Frankham R (2002) Contribution of inbreeding to extinction risk in threatened species. Conserv Ecol 6:16. www.ecologyandsociety .org/vol6/iss1/art16/

> Cassinello J, Gomendio M, Roldan ERS (2001) Relationship between coefficient of inbreeding and parasite burden in endangered gazelles. Conserv Biol 15:1171-1174

> Charlier J, Laikre L, Ryman N (2012) Genetic monitoring reveals temporal stability over 30 years in a small, lakeresident brown trout population. Heredity 109:246-253

Charpentier MJE, Williams CV, Drea CM (2008) Inbreeding depression in ring-tailed lemurs (Lemur catta): genetic diversity predicts parasitism, immunocompetence, and survivorship. Conserv Genet 9:1605-1615

> Congdon JD, Dunham AE, Van Loben Sels RC (1993) Delayed sexual maturity and demographics of Blanding's turtles (Emydoidea blandingii) implications for conservation and management of long-lived organisms. Conserv Biol 7:826-833

Daniels SJ, Walters JR (2000) Inbreeding depression and its effects on natal dispersal in red-cockaded woodpeckers. Condor 102:482-491

Dobie J, Bagley FM (1990) Alabama red-bellied turtle recovery plan. US Fish and Wildlife Service, Jackson, MS

> Earl DA, vonHoldt BM (2012) Structure Harvester: a website and program for visualizing Structure output and implementing the Evanno method. Conserv Genet Resour 4: 359-361

Evanno G, Regnaut S, Goudet J (2005) Detecting the number of clusters of individuals using the software Structure: a simulation study. Mol Ecol 14:2611-2620

Excoffier L, Laval G, Schneider S (2005) ARLEQUIN Ver. 3.0: an integrated software package for population genetics data analysis. Evol Bioinform Online 1:47-50

Freedberg S, Ewert MA, Ridenhour BJ, Neiman M, Nelson CE (2005) Nesting fidelity and molecular evidence for natal homing in the freshwater turtle, Graptemys kohnii. Proc R Soc Lond B Biol Sci 272:1345-1350
Gage MJG, Surridge AK, Tomkins JL, Green E, Wiskin L, Bell DJ, Hewitt GM (2006) Reduced heterozygosity depresses sperm quality in wild rabbits, Oryctolagus cuniculus. Curr Biol 16:612-617

Gibbs JP, Shriver WG (2002) Estimating the effects of road mortality on turtle populations. Conserv Biol 16: 1647-1652

- Guichoux E, Lagache L, Wagner S, Chaumeil P and others (2011) Current trends in microsatellite genotyping. Mol Ecol Resour 11:591-611

Hauser L, Adcock GJ, Smith PJ, Bernal Ramwerez JH, Carvalho GR (2002) Loss of microsatellite diversity and low effective population size in an overexploited population of New Zealand snapper (Pagrus auratus). Proc Natl Acad Sci USA 99:11742-11747

Hieb EE, Jackson TG, Nelson DH, Morris AB (2011) Characterization of eight polymorphic microsatellite loci for the endangered Alabama red-bellied turtle (Pseudemys alabamensis; Emydidae). Conserv Genet Resour 3:781-783

$>$ Holmes EE (2001) Estimating risks in declining populations with poor data. Proc Natl Acad Sci USA 98:5072-5077

> Kalinowski ST (2005) HP-RARE 1.0: a computer program for performing rarefaction on measures of allelic richness. Mol Ecol Notes 5:187-189

> Keller LF, Waller DM (2002) Inbreeding effects in wild populations. Trends Ecol Evol 17:230-241

> King TL, Julian SE (2004) Conservation of microsatellite DNA flanking sequence across 13 emydid genera assayed with novel bog turtle (Glyptemys muhlengergii) loci. Conserv Genet 5:719-725

> Konovalov DA, Manning C, Henshaw MT (2004) KINGROUP: a program for pedigree relationship reconstruction and kin group assignments using genetic markers. Mol Ecol Notes 4:779-782

Leary CJ, Dobie JL, Mann TM, Floyd PS, Nelson DH (2008) Pseudemys alabamensis Baur, 1893-Alabama redbellied cooter, Alabama red-bellied turtle. In: Conservation biology of freshwater turtles and tortoises: a compilation project of the IUCN/SSC Tortoise and Freshwater Turtle Specialist Group. Chelonian Res Monogr 5:019.1019.9. www.iucn-tftsg.org/pseudemys-alabamensis-019/

> Luikart G, England PR, Tallmon D, Jordan S, Taberlet P (2003) The power and promise of population genomics: from genotyping to genome typing. Nat Rev Genet 4: 981-994

Luong LT, Heath BD, Polak M (2007) Host inbreeding increases susceptibility to ectoparasitism. J Evol Biol 20: 79-86

Lynch M, Conery J, Burger R (1995) Mutation accumulation and the extinction of small populations. Am Nat 146: 489-518

Marsh DM, Trenham PC (2008) Current trends in plant and animal population monitoring. Conserv Biol 22:647-655

Nelson DH (2001) Population ecology of the Alabama redbelly turtle (Pseudemys alabamensis) - nesting survey. Final report. Alabama Department of Conservation and Natural Resources, Montgomery, AL

Nelson DH (2003) Nesting activity in the Alabama redbelly turtle (Pseudemys alabamensis) on the Mobile Bay Causeway. Final report. Alabama Center for Estuarine Studies, Mobile, AL

Nelson DH (2009) The monitoring of roadside fencing and road-kill mortality to conserve Alabama red-bellied turtles (Pseudemys alabamensis) along the Mobile Bay Causeway. Annual report, Project 121. Alabama Depart- 
ment of Conservation and Natural Resources, Division of Wildlife and Freshwater Fisheries, Montgomery, AL

Nelson DH (2013) Monitoring of road-kill mortality and road-side fencing along the Mobile Causeway to conserve Alabama red-bellied turtles (Pseudemys alabamensis). Final report, Project 121. Alabama Department of Conservation and Natural Resources, Division of Wildlife and Freshwater Fisheries, Montgomery, AL

Nelson DH, Turner WM (2004) Alabama red-bellied cooter Pseudemys alabamensis Baur. In: Mirarchi RE, Bailey MA, Haggerty TM, Best TL (eds) Alabama wildlife, Vol 3. Imperiled amphibians, reptiles, birds, and mammals. The University of Alabama Press, Tuscaloosa, AL, p 54-55

Nelson DH, Langford GJ, Borden JA, Turner WM (2009) Reproductive and hatchling ecology of the Alabama redbellied cooter (Pseudemys alabamensis): implications for conservation and management. Chelonian Conserv Biol 8:66-73

Oetting WS, Lee HK, Flanders DJ, Wiesner GL, Sellers TA, King RA (1995) Linkage analysis multiplexed short tandem repeat polymorphisms using infrared fluorescence and M13 tailed primers. Genomics 30:450-458

Pritchard JK, Stephens M, Donnelly P (2000) Inference of population structure using multilocus genotype data. Genetics 155:945-959

Queller DC, Goodnight KF (1989) Estimating relatedness using genetic markers. Evolution 43:258-275

Raymond M, Rousset F (1995) GENEPOP (Version 1.2): population genetics software for exact tests and ecumenicism. J Hered 86:248-249

Roldan ERS, Cassinello J, Abaigar T, Gomendio M (1998) Inbreeding, fluctuating asymmetry, and ejaculate quality in an endangered ungulate. Proc R Soc Lond B Biol Sci 265:243-248

Rousset F (2008) GENEPOP'007: a complete reimplementation of the GENEPOP software for Windows and Linux. Mol Ecol Resour 8:103-106

Schwartz MK, Luikart G, Waples RS (2007) Genetic monitoring as a promising tool for conservation and management. Trends Ecol Evol 22:25-33

Scribner KT, Congdon JD, Chesser RK, Smith MH (1993) Annual differences in female reproductive success affect spatial and cohort-specific genotypic heterogeneity in painted turtles. Evolution 47:1360-1373

Souza FL, Cunha AF, Oliveira MA, Pereira GAG, dos Reis SF (2002a) Estimating dispersal and gene flow in the

Editorial responsibility: Jim Groombridge,

Canterbury, UK neotropical freshwater turtle Hydromedusa maximiliani (Chelidae) by combining ecological and genetic methods. Genet Mol Biol 25:151-155

Souza FL, Cunha AF, Oliveira MA, Pereira GAG, Pinheiro HP, dos Reis SF (2002b) Partitioning of molecular variation at local spatial scales in the vulnerable neotropical freshwater turtle, Hydromedusa maximiliani (Testudines, Chelidae): implications for the conservation of aquatic organisms in natural hierarchical systems. Biol Conserv 104:119-126

Staples DF, Taper ML, Shepard BB (2005) Risk-based viable population monitoring. Conserv Biol 19:1908-1916

Tortoise and Freshwater Turtle Specialist Group (1996) Pseudemys alabamensis. In: IUCN Red List of Threatened Species, Ver. 2012.1. Available at: www.iucnredlist. org. (accessed 1 January 2011)

USFWS (United States Fish and Wildlife Service) (1987) Endangered and threatened wildlife and plants: determination of endangered status for the Alabama red-bellied turtle. Fed Regist 52:22939-22943

Valenzuela N (2001) Genetic differentiation among nesting beaches in the highly migratory giant river turtle (Podocnemis expansa) from Colombia. Herpetologica 57:48-57

Waples RS (2006) A bias correction for estimates of effective population size based on linkage disequilibrium at unlinked gene loci. Conserv Genet 7:167-184

Waples RS, Do C (2008) LDNE: a program for estimating effective population size from data on linkage disequilibrium. Mol Ecol Resour 8:753-756

> Waples RS, Do C (2010) Linkage disequilibrium estimates of contemporary $N_{\mathrm{e}}$ using highly variable genetic markers: a largely untapped resource for applied conservation and evolution. Evol Applic 3:244-262

Waples RS, Teel DJ (1990) Conservation genetics of Pacific salmon. I. Temporal changes in allele frequency. Conserv Biol 4:144-156

Whiteman NK, Matson KD, Bollmer JL, Parker PG (2006) Disease ecology in the Galápagos hawk (Buteo galapagoensis): host genetic diversity, parasite load and natural antibodies. Proc R Soc Lond B Biol Sci 273:797-804

- Wildt DE, Bush M, Howard JG, O'Brien SJ and others (1983) Unique seminal quality in the South African cheetah and a comparative evaluation in the domestic cat. Biol Reprod 29:1019-1025

> Wright S (1921) Systems of mating. II. The effects of inbreeding on the genetic composition of a population. Genetics 6:124-143

Submitted: May 31, 2013; Accepted: January 10, 2014 Proofs received from author(s): February 28, 2014 